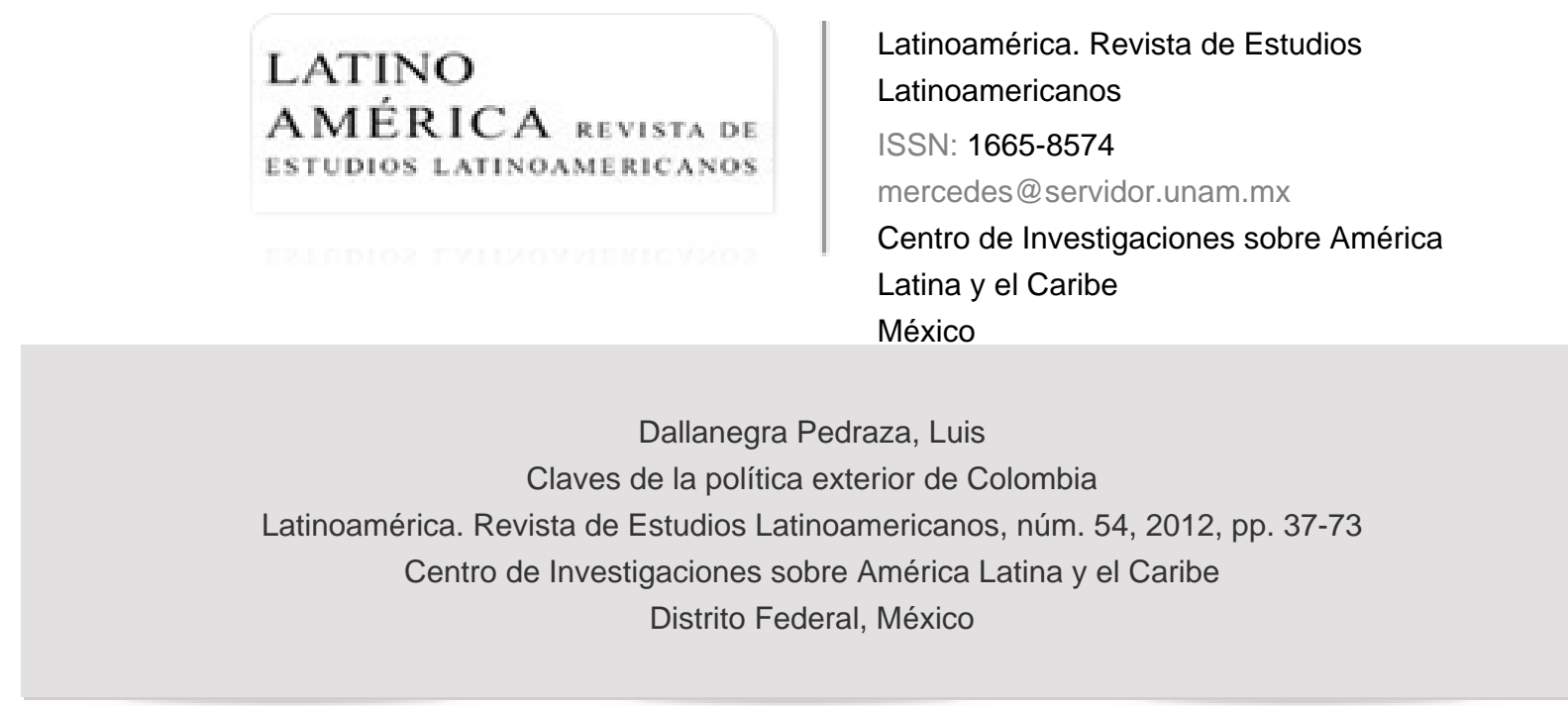

Disponible en: http://www.redalyc.org/articulo.oa?id=64023055003

- Cómo citar el artículo

- Número completo

- Más información del artículo

- Página de la revista en redalyc.org

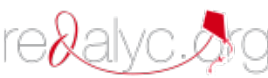

Sistema de Información Científica

Red de Revistas Científicas de América Latina, el Caribe, España y Portugal Proyecto académico sin fines de lucro, desarrollado bajo la iniciativa de acceso abierto 
POLIIICA EXIERIOR LATINOAMERICANA

\title{
Claves \\ de la política exterior de Colombia
}

\author{
Luis Dallanegra Pedraza*
}

Resumen: Colombia, como América Latina, ha sido y es más "objeto" que "sujeto" en la escena internacional. Sus relaciones con Estados Unidos obedecen a lógicas que nada tienen que ver con el orden vigente, sino con opciones políiticas y decisiones de la elite dominante. De acuerdo con las características de esa tendencia, ha estado prácticamente anclada a lo que se denominó simbólicamente como Respice Polum - mirar hacia la "Estrella Polar" — que para este país ha sido Estados Unidos. Ha habido épocas en las que desarrolló una política, simbólicamente llamada Respice Similia — "mirar a los semejantes" — , vinculada a una diversificación de las relaciones en forma más "horizontal" respondiendo al criterio "Sur-Sur"; sin embargo esos momentos han sido tan fugaces y débiles, que sólo demuestran qué tan cerca 0 qué tan lejos se ha estado de Estados Unidos, aunque siempre gravitando en su esfera de influencia.

PalaBRAS CLAVE: Polífica exterior, Historia, Ciencia polííica, Polífica internacional.

ABSTRAC: Colombia, like Latin America, has been and is more an "object" than a "subject" in the international arena. Its relationship with the United States obeys a logic that has nothing to do with the existing order but with politics and decisions by the ruling elite. According to the characteristics of this trend, political decisions have been virtually grounded to what is symbolically called as Respice Polum - to look towards the "Northern Star" - meaning United States. There have been times when the policy was symbolically called Respice Similia — to look at the "similar" - linked to a diversification of relations in a more "horizontal" approach in response to the "South-South" criteria, but these moments are so fleeting and weak that they only show how near or far Colombia has been from the U.S., always gravitating in its sphere of influence.

Key words: Foreign Policy, History, Political Science, International Policy.

Consejo Nacional de Investigaciones Científicas y Técnicas (CONICET), Argentina (luisdallanegra @gmail.com)

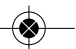


Luis Dallanegra Pedraza

\section{INTRODUCCIÓN}

1 sistema internacional está formado por estados que se interrelacionan e intercondicionan en forma asimétrica, estableciendo una estructura que condiciona la manera en que se relacionarán, situando los límites dentro de los que cada uno podrá actuar independientemente. ${ }^{1}$ Para tomar decisiones sobre política exterior, es necesario tener claro cuáles son las "características estructurales" del sistema; caso contrario, los costos de las decisiones, serán mayores que los beneficios que se obtengan. La mayoría piensa la políica exterior en términos de "relaciones exteriores" y no de logro de objetivos en función de los intereses nacionales. Las relaciones exteriores muestran los vínculos pero no lo alcanzado; la política exterior es el diseño para lograr objetivos concretos en cuanto a desarrollo e inserción mundial. Teniendo en cuenta el marco global histórico y las características de la estructura en el sistema, es posible discernir cuáles son las características básicas de la política exterior de un país. Ellas se derivan, por un lado, de la estructura y del régimen internacional ${ }^{3}$ y, por otro, de la "percepción" que de esa estructura tiene la élite gobernante y del modelo de inserción que elabora. Esto es aplicable a toda América Latina; no obstante, me concentraré en el caso colombiano.

\section{CARACTERÍSTICAS BÁSICAS DE LA POLÍTICA EXTERIOR}

Una característica dominante e histórica de la política exterior de Colombia -sin grandes diferencias con las de otros países en la región - es la inserción "racional" dependiente de la principal potencia de rango mundial. Las relaciones de Colombia con el resto del mundo han estado fuertemente influidas por sus

1 Límites dentro de los que el sistema permite que los miembros asimétricamente tengan desempeños independientes, más allá de los que el sistema usa mecanismos de control para reprimir y frenar las conductas que puedan perjudicar su equilibrio. A este mecanismo lo llamo "proceso homeostático". Luis Dallanegra Pedraza, El Orden Mundial del Siglo xxI, Buenos Aires, Ediciones de la Universidad, 1998, p. 15.

2 Configuración de poder en forma asimétrica.

3 Marco institucional resultante de la configuración estructural. 
vínculos con Estados Unidos. Hay una convicción generalizada en las élites políticas, económicas e intelectuales, de que la vinculación dependiente es deseable como estrategia para ubicar al país en posiciones de privilegio internacional. Colombia, como América Latina, ha sido y es más "objeto" que "sujeto" en la escena internacional. Sus relaciones con Estados Unidos obedecen a lógicas que nada tienen que ver con el orden vigente, sino con opciones políticas y decisiones de la élite dominante que "arrastran al Estado en la dirección de sus intereses". De acuerdo con la característica mencionada, ha estado prácticamente anclada a lo que se denominó simbólicamente como Respice Polum -mirar a la Estrella Polar - que para este país, ha sido Estados Unidos. Algunos consideran que ha habido épocas en las que ha desarrollado una política, simbólicamente llamada Respice Similia -mirar a los "semejantes" - ${ }^{4}$ vinculada a una diversificación de las relaciones en forma "horizontal" respondiendo al criterio Sur-Sur; sin embargo esos momentos han sido tan fugaces y débiles, que sólo demuestran qué tan cerca o lejos se ha estado de Estados Unidos, aunque siempre gravitando en su esfera de influencia. ${ }^{5}$ ¿Por qué Respice Polum y no Respice Similia? En muchos casos se dan factores que hacen que no sea posible llevar a cabo alianzas y menos de carácter estratégico entre miembros periféricos. Entre estos factores se encuentran: $a$ ) la percepción de que la vía individual es la más adecuada; $b$ ) la idea de que la carga de los compromisos que surgen de una alianza son un contrapeso frente a las ventajas que se espera conseguir; $c$ ) la creencia de que los vínculos con el hegemón son más ventajosos; $d$ la lesconfianza existente entre los gobiernos de una misma región o que tienen la misma

4 En América Latina los gobiernos que se han ido sucediendo, privilegiaron sus vínculos con la potencia hegemónica o con los "semejantes" en lo que hace a problemáticas y objetivos, pero una u otra conducta no se ha mantenido constante, debido a la gran cantidad de golpes de Estado o a los diferentes vaivenes partidistas. Luis Dallanegra Pedraza, "El sistema político latinoamericano", en Revista Reflexión Política, vol. V, núm. 10, diciembre de 2003, Instituto de Estudios Políticos, Universidad Nacional Autónoma de Bucaramanga, pp. 6-32.

5 Martha Ardila, Diego Cardona y Arlene B. Tickner, Prioridades y desafíos de la politica exterior colombiana, Bogotá, Friedrich Ebert Stiftung, 2002; Rodrigo Pardo, "La política exterior", en Fernando Cepeda Ulloa [ed.], Fortalezas de Colombia, Bogotá, Planeta/Banco Interamericano de Desarrollo, 2004

latino mérica 54

(MÉxico 2012/1): 37-73 39 
Luis Dallanegra Pedraza

problemática; e) la inestabilidad y/o discontinuidad de las políticas y/o gobiernos. La política exterior, histórica y actual, de la mayoría de los países de América Latina, se inscribe en estos factores. ${ }^{6}$ Una segunda característica, es que Colombia, luego de la etapa de predominio "bolivarista", se ha mantenido aislada del contexto regional y sus vínculos mundiales han sido escasos. En general, América Latina ha mantenido vínculos externos fuera de la región, ya que su élite dirigente y pensante consideró que las prioridades y posibles ventajas se encontraban en relacionarse con actores extrarregionales, particularmente Europa y Estados Unidos. La relación entre Estados Unidos y Colombia es asimétrica y con diferente nivel de agenda: para Estados Unidos su conexión con Colombia está definida por sus intereses basados en la seguridad y lo económico-comercial-financiero; para Colombia, está centrada en la viabilidad de la agenda interna, vinculada a la élite dominante. Lo que para Estados Unidos es una relación pragmática y no vital, para Colombia se ha convertido en requisito de supervivencia interna: grandes recursos en cooperación económica y militar y externa: garantizar su viabilidad internacional. Los gobiernos colombianos han llevado a cabo más una "diplomacia personal y corporativa" que una política exterior, en términos de buscar una mejor inserción del país junto a la satisfacción de los objetivos basados en el interés nacional. La política externa de Estados Unidos hacia la región, siempre ha estado ligada a sus intereses de seguridad y económicos, privilegiando más a algunos estados que a otros en función de factores estratégicos y del grado de funcionalidad de sus gobiernos. La región ha considerado que sus vínculos con Estados Unidos son esenciales para obtener ventajas en materia de comercio exterior, inversiones y el voto favorable en los organismos multilaterales de pago. Una tercera característica tiene que ver con la "debilidad en la política territorial". Esta se inició con la pérdida del istmo de Panamá a lo que hay que agregar la inexistencia de una "talasopolítica", más aún, siendo un país bioceánico. Como cuarta característica, relacionada a

6 Luis Dallanegra Pedraza, Realismo-Sistémico-Estructural: la Politica Exterior como "Construcción" de Poder, Córdoba, edición del autor, 2009.

7 "Talaso" del griego: mar. Política marítima. Prácticamente toda América Latina, con excepción de Brasil vive de "espaldas" al mar.

(México 2012/1): 37-73

latino @mérica 54 
prácticamente el resto de América Latina, es que en vez de generar mecanismos para "construir poder" que le permita alcanzar una mayor autonomía de desempeño, ha utilizado el derecho como instrumento privilegiado de la política exterior. La mayoría de los analistas de la política exterior colombiana ${ }^{9}$ coincide en atribuirle un marcado corte "juridicista", presuponiendo que la actuación internacional ha tenido, tradicionalmente, un enfoque legalista - para esta forma de pensar, las relaciones internacionales se basan en la adopción de acuerdos y tratados y en las instituciones internacionales-, llegando a la defensa de principios jurídicos por encima de actuaciones de conveniencia política y de "construcción de poder"10 para lograr una mayor autonomía de desempeño. Dos ejemplos muestran su tendencia "juridicista": uno dado por la política adoptada frente al conflicto de las Malvinas, ${ }^{11}$ en contra de toda América Latina; el otro por su postura frente a Panamá. Por otra parte, le ha dado una significación variable a la política económica, en función de la corriente ideológica y la percepción dominante. Existe un régimen de "diplomacia económica-comercial" paralelo o "paradiplomacia" al margen de la política pública, ejercido por los gremios correspondientes, especialmente del café. La defensa de los intereses y las bases económicas de la política exterior, casi siempre, se hizo fuera de cancillería. El concepto de integración, como en la mayoría de los países latinoamericanos, es el de "libre comercio" y no contempla la idea de "alianza estratégica" para maximizar la capacidad de desempeño internacional orientada a la construcción de poder. A la política exterior colombiana no se la considera política de "Estado" sino de "Gobierno".

8 Prácticamente toda América Latina, históricamente y en la actualidad - salvo excepciones-, ha desarrollado más una "jurídica exterior" que una "política exterior". Juan Carlos Puig, "Tendencias de la política exterior argentina", en Doctrinas internacionales y autonomía latinoamericana, Caracas, Universidad Simón Bolívar, 1980.

9 Lo mismo se puede decir de otros países latinoamericanos cuya política exterior se haya estudiado. Argentina es un caso paradigmático.

${ }^{10}$ Dallanegra Pedraza, Realismo-Sistémico-Estructural..

${ }^{11}$ Colombia, junto a Chile, Estados Unidos y Trinidad y Tobago se abstuvieron en la votación del TIAR, aduciendo el incumplimiento argentino de la Resolución 502 de la onu. Luis Dallanegra Pedraza, Relaciones Políticas entre Estados Unidos y América Latina: iPredominio "Monroista" o Unidad Americana?, Buenos Aires, edición del autor, 1994, cap. XVII. 
Luis Dallanegra Pedraza

\section{GOBIERNOS Y POLÍTICA EXTERIOR}

\section{Nacimiento de la Doctrina de la Inserción "racional" dependiente}

El concepto de "inserción racional dependiente" implica, no sólo un vínculo de filiación en relación con la potencia hegemónica, sino y fundamentalmente, la idea de que la élite dirigente y pensante tiene la percepción de que mantener lazos de subordinación es más adecuado para los intereses del país, que adoptar conductas autonómicas. Esta concepción no ha sido ni exclusiva ni excluyente de ningún país o gobierno latinoamericano. La región ha ido evolucionando casi permanentemente dentro de estos carriles, con algunos cambios fallidos, buscados de manera poco prudente, por gobiernos que consideraron que la construcción de posiciones autónomas era resultado más de un cambio de discurso que de la construcción de poder en forma subrepticia en el largo plazo. ${ }^{12}$ En Colombia fue Marco Fidel Suárez, un conservador que dirigió varias veces el Ministerio de Relaciones Exteriores - la última entre 1914 y 1918-, quien confirmó, al asumir la presidencia en 1918, el cambio de órbita del país en el terreno de la política internacional. La Primera Guerra Mundial había acentuado la transferencia de los mercados externos de Europa hacia Estados Unidos y había dejado fortalecido a éste y debilitado al imperio inglés. Los capitales que necesitaba el país para su desarrollo, para la explotación del petróleo, la apertura de vías de comunicación y el mejoramiento de los servicios públicos, en opinión de los principales dirigentes económicos del país, sólo podía venir de Estados Unidos. Suárez señaló la necesidad de orientar la política nacional en función de la nueva situación internacional y tener en cuenta el papel creciente de Estados Unidos. "Mirar al Norte" o "buscar en el Polo" Respice Polum debía ser la guía esencial de este reordenamiento. ${ }^{13}$ Para ello, era esencial lograr que Estados Unidos aprobara el Tratado Urrutia-Thomson, cuyo objetivo era solucionar el conflicto entre estadounidenses y colombianos, provocado por el apoyo de aquel país a la se-

${ }_{12}$ Dallanegra, Realismo-Sistémico-Estructural...

${ }_{13}$ Durante el gobierno de Suárez, también se desarrollaron vínculos "borizontales", aunque no los profundizó. 
paración de Panamá en 1903. ${ }^{14}$ Fue un arreglo a espaldas de Panamá. El 22 de agosto de 1920 se dio en el Senado el primer debate al proyecto de tratado con Estados Unidos, entre los que eran partidarios y sus enemigos. El 4 de septiembre renunció el gabinete por la pugna entre el Ejecutivo y el Congreso. La oposición a las medidas gubernamentales era total. En noviembre, se establecieron las bases para arreglar las relaciones entre el Parlamento y el gobierno y los problemas relativos a la firma del tratado que ya había sido aprobado en Estados Unidos. Marco Fidel Suárez dio su palabra de hacer todo lo que estuviera en su poder para que el tratado fuera aprobado en Colombia, incluyendo su renuncia. Se acordó que la Cámara de Representantes pondría todo su empeño para que el proyecto fuera considerado y resuelto definitivamente en el menor tiempo posible. La verdadera cuestión era conseguir los 25 millones de dólares de la indemnización, ya que con eso se lograría sacar adelante al país. El 9 de noviembre de 1921, Suárez envió al presidente del Senado una nota en la que le avisaba su separación de la presidencia. El 11 se separó del poder y el primer designado, el general Jorge Holguín Mallarino, asumió el mando. ${ }^{15}$ El 24 de diciembre fue sancionada la Ley 56/1921 aprobatoria de las modificaciones al tratado con Estados Unidos. ${ }^{16}$ En virtud de este tratado, acordaban: 1. El derecho de Colombia de transportar tropas, buques y materiales de guerra sin pagar peaje por el Canal de Panamá. 2. El pago a Colombia de 25 millones de dólares, en indemnización por la separación de Panamá. 3. El reconocimiento por Colombia de Panamá y la fijación de límites fronterizos de conformidad a lo indi-

${ }^{14}$ En 1901, Estados Unidos y Gran Bretaña habían firmado el Tratado Hay-Pauncefote, en el que se establecía una división expresa de "esferas de influencia" en América Latina, al otorgarle a Estados Unidos la responsabilidad por la construcción de un Canal interoceánico en el Istmo de Panamá, a la vez que por la seguridad de la región. Dallanegra Pedraza, Relaciones Políticas entre..., p. 10

${ }^{15}$ Jorge Holguín fue ministro de Relaciones Exteriores con el presidente Miguel Antonio Caro 1892-1898 y ministro de Guerra en las administraciones de Manuel Antonio Sanclemente 18981900 y Rafael Reyes 1904-1909. Cuando ocurrieron los hechos del "Trecemarcismo" que culminó con la renuncia del presidente Rafael Reyes, ejerció el Poder Ejecutivo en calidad de designado, desde el 9 de junio de 1909 hasta el 4 de agosto de ese año en que le entregó la presidencia a Ramón González Valencia.

${ }^{16}$ Heriberto Marco Zapata Cuéncar, Fidel Suárez, Medellín, Copymundo, 1981. 
Luis Dallanegra Pedraza

cado en la Ley colombiana del 9 de junio de 1855. 4. La exoneración de impuestos a los productos agropecuarios y de la industria colombiana que pasaran por el canal, así como el correo. Panamá no tuvo participación en la negociación del tratado ni le dio el derecho a Estados Unidos para que actuara en su nombre. Al aprobarse el tratado, el gobierno de Panamá protestó y no reconoció los límites. ${ }^{17}$ El general Jorge Holguín Mallarino sirvió de enlace entre el Ejecutivo y el Legislativo, que tenían dificultades. Pese a la invitación hecha al liberalismo para que participara en el gobierno, no obtuvo colaboración. Además de lograr la aprobación del Tratado Urrutia-Thomson, dio las instrucciones para la firma del Pacto Lozano-Salomón, iniciado en el gobierno anterior, para dar fin al conflicto de límites con Perú.

\section{Impulso a las vías de comunicación}

Quien utilizó los 25 millones de dólares de la indemnización que pagó Estados Unidos por la separación de Panamá, fue el general Pedro Nel Ospina Vásquez, quien asumió la presidencia en 1922. Con agregado de crédito extranjero, invirtió en el desarrollo de las vías de comunicación. Los ferrocarriles recibieron un gran impulso, posibilitando incrementar las exportaciones de café. Construyó el Ferrocarril del Pacífico y firmó el contrato para la edificación del muelle de Buenaventura. Favoreció la aviación comercial de pasajeros y correo, con la constitución de la empresa colombo-alemana CSADTA, primera compañía de aviación en América Latina. Construyó el oleoducto Barrancabermeja-Cartagena, inaugurado en junio de 1926. La base industrial del país se fue ampliando durante la década de 1920, sobre todo entre 1925 y 1930, periodo que fue considerado como uno de los de mayor crecimiento económico en toda la historia nacional. La base técnica de ramas industriales como la textil, comenzó a expe-

${ }^{17}$ Jorge Sánchez Camacho, Marco Fidel Suárez: biografía, Bucaramanga, Imprenta del Departamento, 1955. También, Raimundo Rivas, Historia diplomática de Colombia 1810-1934, Bogotá, Ministerio de Relaciones Exteriores/Imprenta Nacional, 1961.

(MÉxico 2012/1): 37-73

latino @mérica 54

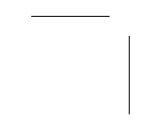


rimentar transformaciones debido a la introducción de equipos automáticos. Uno de los principales actos de gobierno fue traer, en 1924, la misión de expertos extranjeros financieros, dirigida por Edwin Walter Kaemmerer, ${ }^{18}$ que organizó el Ministerio de Hacienda y de Crédito Público para la recaudación de rentas e impuestos y la regulación de gastos y creó la Contraloría General de la República. Ese mismo año restableció las relaciones con Panamá y firmó los límites definitivos entre las dos naciones, que fueron determinados por el Tratado Victoria-Vélez, el 20 de agosto de 1924; los mismos que fijó la ley de 1855. También fijó los límites terrestres con Venezuela, que se habían empezado a discutir en la administración de José Vicente Concha.

\section{CRISIS ECONÓMICA MUNDIAL 1929/1930}

\section{Y CONFLICTIVIDAD TERRITORIAL EN LA REGIÓN}

Colombia pasó varios años y gobiernos tratando de resolver problemas de límites. Gran parte de la política exterior del denominado "último presidente de la Hegemonía Conservadora", Miguel Abadía Méndez, que asumió la presidencia en 1926, estuvo vinculada a la resolución de límites fronterizos. Estableció los límites marítimos con Nicaragua en el Tratado Esguerra-Bárcenas 24-3-1928 pasando el archipiélago de San Andrés, Providencia y Santa Catalina a soberanía colombiana mientras que la Costa de Mosquitos pasaba a soberanía nicaragüense. Los límites con Brasil se acordaron con la firma del tratado entre el canciller brasileño Octavio Mangabeira y el ministro plenipotenciario de Colombia en Río de Janeiro, Laureano García Ortiz el 15-11-1928, con el que se protocolarizaron todas las ocupaciones que había realizado ese país por las vías de hecho, de la hoya del Amazonas, del Caqueta y del Putumayo. En compensación por las cesiones territoriales, Colombia adquirió el derecho de navegación por el río Amazonas. Debido a la crisis mundial de 1929, enfrentó graves pro-

${ }^{18}$ Las "misiones Kaemmerer" formaron parte de la política del "dólar" por parte de Estados Unidos en la región.

latino:gérica 54

(MÉxxco 2012/1): 37-73 45 
Luis Dallanegra Pedraza

blemas políticos y económicos que amenazaron con una parálisis financiera y de la producción y con conflictos sociales; ${ }^{19}$ en parte debido a la política de incrementar la deuda externa por recurrir a empréstitos para no detener las obras públicas más importantes y también por los precios a la baja del café. El desgaste del gobierno contribuyó a debilitar al partido conservador, posibilitando la llegada de un liberal al poder: Enrique Olaya Herrera. Siguió los criterios del Respice Polum con dos prioridades claras: un entendimiento con Estados Unidos, al otorgarle ventajas en materia de explotación del petróleo y la guerra con Perú. La explotación del caucho había sido uno de los grandes rubros de exportación a principios del siglo y una firma peruana, la Casa Arana, se había establecido desde Iquitos hasta bien entrados los afluentes del Amazonas en territorio colombiano. En febrero de 1933 estalló el conflicto entre Colombia y Perú, vinculado al petróleo y látex existente en la región y a desentendimientos respecto del Tratado Salomón-Lozano de delimitación territorial. La deuda externa creció y algunos de los compromisos no pudieron ser mantenidos debido al costo de la guerra con Perú. Se intentó atraer capital extranjero por la vía de ventajas impositivas y arancelarias y condiciones muy favorables a los inversionistas. Las facilidades otorgadas a las inversiones extranjeras, y muy en particular a la inversión petrolera, se convirtieron en el instrumento económico por excelencia de esta administración. Como consecuencia de los problemas económicos de Alemania, Inglaterra y Francia por la crisis del treinta, las exportaciones colombianas descendieron sensiblemente, contribuyendo a la crisis financiera. Por esa razón y en busca de mercados e inversionistas, el presidente Olaya desarrolló una política exterior muy cercana a Estados Unidos. El 30 de abril de 1933 fue asesinado, por un militante del "aprismo", el presidente peruano Luis Miguel Sánchez Cerro. Su sucesor, el general Oscar Benavides, amigo del recién electo presidente colombiano Alfonso López Pumarejo, jefe del Partido Liberal, se reunió con él en Lima. Perú aceptó entregar Leticia a una comisión de la Sociedad de Naciones, que estudió alternativas de solución al conflicto. Colombia entregó

${ }^{19}$ Masacre de las Bananeras en diciembre de 1928. Solución militar al conflicto laboral entre la United Fruit Company y sus trabajadores.

(México 2012/1): 37-73

latino @mérica 54 
a Perú la guarnición de Güepí después de la firma del cese de hostilidades. Colombia y Perú se reunieron luego en Río de Janeiro el 19 de marzo de 1928 para pactar la paz y quedó ratificado el Tratado Salomón-Lozano de 1922. El primer periodo de López Pumarejo coincidió con el desarrollo del New Deal en Estados Unidos; sin embargo, el modelo económico buscado, estaba mucho más cerca del Reino Unido. En los dos periodos de gobierno de López Pumarejo, América Latina pasó a ser una importante prioridad geográfica, con el criterio del Respice Similia. En lo económico, no se otorgó exclusividad al tema del servicio de la deuda, tal vez porque ya habían ingresado algunos capitales o porque los precios de algunas materias primas, en el primer periodo, habían ascendido. Tuvo, al igual que la mayoría de los gobiernos latinoamericanos, una visión "juridicista"20 de la política exterior. Auspició la reglamentación interna con algunas restricciones a los productores de banano y a las compañías petroleras extranjeras. En su segundo periodo, puso énfasis en la participación del país en la construcción del marco institucional que dio origen a la onu, el fMI y el BIRF. La participación en Naciones Unidas fue en consenso con el partido conservador.

\section{Segunda GuerRa Mundial}

\section{La concentración en el mercado de Estados Unidos}

En 1938, asumió la presidencia en Colombia Eduardo Santos Montero, a quien le tocó gobernar en un contexto mundial en guerra, dificultando la posibilidad de diversificar mercados para los productos colombianos. Este gobierno, caracterizado por seguir las pautas del Respice Polum, continuó sin embargo, con una cercanía relativa al modelo británico. Fue llamado "gobierno de pausa" porque frenó el impulso de los cambios planteados por su antecesor Alfonso López Pumarejo. Estados Unidos se convirtió, por primera vez, en el principal mercado para los productos colombianos, al que exportó las cuatro quintas partes del café, el petróleo y el oro, debido a la Segunda Guerra Mundial y a las difi-

${ }^{20}$ Puig, op. cit.

latino gुmérica 54

(MÉxico 2012/1): 37-73 47 
Luis Dallanegra Pedraza

cultades de transporte de los productos hacia los mercados europeos. Para asegurarse el mercado norteamericano, incluyó al país en la "Alianza Continental", promovida por Estados Unidos contra las potencias del Eje. ${ }^{21}$ Normalizó la deuda externa, pese a que la guerra trajo consigo una menor demanda de productos colombianos y una baja en los precios. En el Sistema Interamericano, apoyó las iniciativas propuestas por el gobierno norteamericano, e incluyó a Colombia en el Convenio latinoamericano de productores de café, que sentó las bases del pacto internacional del café; mecanismo importante para la autorregulación de las cuotas por los productores, con lo que podía mantenerse un nivel relativamente alto en los precios.

\section{Post-Segunda Guerra Mundial y Guerra Fría}

Pese al cambio de sistema mundial, con características totalmente diferentes al que imperó durante el siglo xix y principios del xx, Colombia -al igual que la gran mayoría de estados latinoamericanos- no modificó la manera de insertarse en el mundo. En 1945 asumió la presidencia Alberto Lleras Camargo, quien se encontró con una situación económica compleja y un escenario político que se había deteriorado. La política externa de Lleras Camargo continuó con la perspectiva "juridicista" respecto de las características y funcionamiento del sistema internacional, bajo el "espejismo" de que adoptar posiciones diferentes en materia de aplicación e interpretación del Derecho Internacional permitía un mejor posicionamiento del país en la comunidad de naciones y no la estructura de poder. Durante su presidencia, Colombia expresó su oposición al derecho a veto de los miembros permanentes del Consejo de Seguridad de la onu. Esta posición, compartida sólo por Cuba en su momento, tenía una perspectiva con base jurídica más que de políica de poder, ya que planteaba que todos los países debían ser iguales ante la ley internacional. La posición de Colombia no tenía esta motivación, sino la de avanzar en los criterios que en algún momento irían a

${ }^{21}$ Dallanegra, Relaciones Políticas entre..., cap. VIII. 
orientar a una futura Organización de Estados Americanos que se creó en 1949, sin derecho a veto por parte de la potencia hegemónica.

\section{Pacto entre liberales y conservadores}

En su segunda administración que comenzó en 1958 se inauguró el Frente Nacional, del que fue coautor. Respecto de este tema hay dos hechos dignos de mención: 1. El Frente Nacional constituía un tratado de paz entre los dos partidos tradicionales. 2. Como todo acuerdo de paz políico, condujo a una importante reforma de la Constitución. De esa forma Colombia era vista en el exterior como un país que había logrado superar sus disputas internas por la vía de un acuerdo político. En 1962 convocó a la 8a Reunión de Consulta de Ministros de Relaciones Exteriores, para tratar el caso cubano e imponerle sanciones debido a la posible intervención de potencias extra continentales que atentaran contra la paz y estabilidad de la región con ideologías extrañas. Que el primer presidente del Frente Nacional fuera quien había sido el primer Secretario General de la OEA, le dio a su mandato peso diplomático y una gran legitimidad. Colombia fue la vitrina de la Alianza para el Progreso propuesta por Estados Unidos y el país piloto para una serie de cambios en la estructura del Estado, la administración pública y la visión del modelo económico que se pretendía para América Latina. Es este el periodo en el que Colombia ha estado más cerca de Estados Unidos.

\section{Inicio de la Coexistencia Pacífica: Kennedy-Kruschev}

\section{"Latinoamericanización" de la política exterior}

A partir de la presidencia de Carlos Lleras Restrepo en 1966, con algunas excepciones importantes, ${ }^{22}$ Colombia comenzó a reorientar su política exterior hacia sus vecinos de América Latina, y otros países fuera de la región, especial-

${ }^{22}$ Durante el gobierno de Turbay Ayala 1978-1982, la política exterior del país se caracterizó por un alineamiento renovado hacia Estados Unidos.

latino @mérica 54

(MÉxxico 2012/1): 37-73 49 
Luis Dallanegra Pedraza

mente Europa y Asia, ${ }^{23}$ con el fin de diversificar sus vínculos internacionales, así como lograr un mayor campo de acción en el sistema internacional. En consecuencia, se adoptó la doctrina del Respice Similia, o "mira a tus semejantes" -término acuñado por Alfonso López Michelsen, ministro de Relaciones Exteriores de Lleras Restrepo y más adelante, presidente de la República 1974-1978-. De acuerdo con la orientación de este principio, Colombia buscó un mayor protagonismo entre sus vecinos latinoamericanos, en coincidencia con transformaciones en las orientaciones de la política externa de América Latina. En términos generales, los países de la región buscaron tener una mayor influencia internacional, además de una mayor autonomía regional respecto de Estados Unidos, actor que veía disminuida su hegemonía en el hemisferio. ${ }^{24}$ En el juego de la política mundial, buscaba dejar de ser "simple peón de la Guerra Fría". Su concepto como presidente, era que su tarea estaba en la lucha en pro de universalizar la política internacional de Colombia. ${ }^{25}$ La política exterior estaba determinada por las relaciones económicas; por ello intentó diseñar una política externa orientada a procurar la emancipación económica. ${ }^{26}$ Criticó la Alianza para el Progreso, que se llevó más de los ahorros de la región de los que invirtió en ella. ${ }^{27}$ Tuvo un gran protagonismo en la búsqueda de la firma del Tratado Torrijos-Carter. También restableció las relaciones diplomáticas con Cuba luego de más de una década de ruptura.

${ }^{23}$ Enrique Neira Fernández, "Colombia: política exterior observatorio de Política Internacional", en Frontera, 14 de agosto, 2008. En http://www.saber.ula.ve/bitstream/123456789/13635/1/colombia_10042008.pdf.

${ }^{24}$ Abrahan Lowenthal, "El fin de la presunción hegemónica", en Estudios Internacionales, vol. I, núm. 37, 1977; Arlene B. Tickner, "Tensiones y contradicciones en los objetivos de la política exterior estadounidense en Colombia: consecuencias involuntarias de la política antinarcóticos de Estados Unidos en un estado débil", en Revista Colombia Internacional, núms. 49/50; J. L. Fiori, O Poder Global e a Nova Geopolítica das Nações, São Paulo, Boitempo, 2007, p. 38.

${ }^{25}$ Arturo Frondizi de Argentina y Janio Quadros de Brasil tenían la misma idea y lo dejaron expreso cuando firmaron el "Acuerdo de Uruguavana" de 1961.

${ }^{26}$ Roberto González Arana, "La política exterior de Colombia a finales del siglo xx: primera aproximación”, en Investigación y Desarrollo, vol. 12, núm. 2, 2004, pp. 258-285.

${ }_{27}$ F. Cepeda Ulloa y R. Pardo, "La política exterior colombiana 1974-1986", en Nueva Historia de Colombia, Bogotá, Planeta, 1989, p. 59. 


\section{ReINICIO DE LA GUERRA FRía}

\section{Retorno a la inserción "racional" dependiente}

La presidencia de Julio César Turbay Ayala, a partir de 1978, se caracterizó por la búsqueda del retorno al modelo clásico de relaciones exteriores; aunque en un comienzo continuó con algunos conceptos trazados por el gobierno anterior en materia internacional, como diversificar las relaciones exteriores del país, ${ }^{28}$ esta orientación no tardó en claudicar para retornar al Respice Polum, a partir del segundo año de su mandato. Para justificar su políica, decía: "es una verdad indiscutible que nos movemos en la órbita en la que Estados Unidos, la primera superpotencia mundial de Occidente, ejerce su mayor influencia". ${ }^{29}$ Durante el gobierno de Ronald Reagan 1981-1989, Turbay, quien estaba interesado en recuperar la imagen exterior del país, deteriorada por el narcotráfico, obsesionado por ocupar un lugar importante en el Caribe e interesado en combatir la insurgencia interna, contó con el apoyo irrestricto de Estados Unidos. La subordinación total se evidenció en el rechazo colombiano a la Declaración Franco-Mexicana, que recomendaba una negociación entre la guerrilla y el gobierno salvadoreño; la participación del país como observador en las elecciones salvadoreñas de 1982, al legitimar a un régimen dictatorial; el solitario respaldo a Inglaterra, Estados Unidos y Chile - con la dictadura de Pinochet- en la Guerra de las Malvinas 1982; ${ }^{30} \mathrm{el}$ envío de tropas al Sinaí y la ruptura de relaciones diplomáticas con Cuba, que habían sido restablecidas por su antecesor. Independientemente del acercamiento a Estados Unidos, defendió la bandera de los derechos humanos ante la Guerra Civil nicaragüense, donde la sociedad civil se alzaba en armas contra la dic-

${ }^{28}$ Por primera vez Colombia asistió, como observador, a una cumbre del Movimiento de Países No Alineados (MONOAL), La Habana, septiembre, 1979 y entabló contacto con la Yugoslavia de Tito. Anunció la apertura hacia África y estableció relaciones diplomáticas con China Popular, al igual que la mayoría de los países latinoamericanos, luego del acercamiento del gobierno de Nixon a través de Kissinger.

${ }^{29}$ Cepeda y Pardo, op. cit., p. 59.

${ }^{30}$ Acción que motivó el repudio de muchos países del continente lo que dio pie para que se tildase a Colombia como el "Caín latinoamericano", pues contrariaba al tiar que instaba a la solidaridad con cualquier país americano que fuese agredido por una potencia internacional. El 
Luis Dallanegra Pedraza

tadura de Somoza. El pronunciamiento de los presidentes de Colombia y Venezuela ante la ONU -septiembre de 1979-que cuestionaron al régimen "somocista" por la violación de los derechos humanos, fue una importante bandera del gobierno de Turbay Ayala. Pero tenía una política dual: defensa de los derechos humanos en lo internacional y utilización de la represión como medio para sofocar el conflicto social interno. Utilizar como bandera los derechos humanos se explica durante su primer año de gobierno, porque coincidía con la principal preocupación de Estados Unidos. ${ }^{31}$ Turbay seguía los pasos de la administración de Jimmy Carter (1977-1981), que asumía una postura dual cuando apoyaba a varias dictaduras en el continente y censuraba a otras. Con la caída de la dictadura de Somoza en Nicaragua, en julio de 1979, se extinguió el referente sobre el que el gobierno liberal colombiano desviaba las acusaciones que recibía del exterior. La situación de los derechos humanos en el país había trascendido tanto, que no le quedó otra salida que reorientar su estrategia de política exterior. A medida que Turbay iba adquiriendo el respaldo norteamericano para concretar proyectos de inversión internos o de defensa nacional, sus vínculos con Estados Unidos fueron pasando de la colaboración, durante el gobierno de Jimmy Carter, a la subordinación incondicional a partir de la presidencia de Ronald Reagan. ${ }^{32}$

Fin de la Segunda Guerra Fría - ReyKjavik 1985

\section{Intento de "Diversificación" de la Política Externa}

El gobierno de Belisario Betancur asumido en 1982, al menos durante sus primeros dos años, intentó desligarse del alineamiento automático con Estados Uni-

gobierno chileno de Pinochet adoptó postura similar al ayudar al gobierno británico logísticamente durante la guerra. Arturo Gálvez Valega, Sistema Interamericano de Defensa, Barranquilla, Uninorte, 2002; Dallanegra, Relaciones Políticas entre..., cap. XVII.

${ }^{31}$ C. Nasi, "La política internacional de Colombia hacia Cuba y Nicaragua durante el gobierno del presidente Julio César Turbay Ayala, 1978-1982", en Documentos CEI, núm. 9, mayo-junio de 1989, Universidad de los Andes, p. 16.

${ }^{32}$ Loc. cit. 
dos. La novedosa propuesta de incorporar a Colombia en el Movimiento de Países No Alineados (MONOAL), la búsqueda de salidas multilaterales a problemas latinoamericanos como la deuda externa y el conflicto centroamericano fueron políticas que allanaron el camino para que el país lograse un reconocido liderazgo internacional. Colombia, con Betancourt, pasó a ser crítica de Estados Unidos; ${ }^{33}$ de no apoyar a Argentina en su guerra por las Malvinas, pasó a apoyarla en la etapa del gobierno de Raúl Alfonsín 1983-1989; del distanciamiento y fricción con Nicaragua y una pasiva política en la región pasó al acercamiento y búsqueda de salidas conjuntas para la crisis centroamericana, participando de la creación del Grupo de Contadora en 1983 junto a México, Panamá y Venezuela; de unas tensas relaciones con Cuba pasó a un momento de distensión e histórico acercamiento..$^{34}$ Estas nuevas orientaciones partían de admitir que era más ventajoso para el país una novedosa estrategia en políica exterior, más autónoma respecto de Estados Unidos ${ }^{35} \mathrm{y}$ también respondían a las nuevas tendencias internacionales post-Reykjavik $1985 .^{36} \mathrm{En}$ el tema de la deuda externa latinoamericana, cuya crisis se inició con el default declarado por el gobierno de México en 1982, la administración de Betancur planteó, en diferentes foros y al gobierno de Reagan, que fuese renegociada, de forma tal que los pagos que se debían realizar se fijaran en un porcentaje previamente establecido sobre los ingresos recibidos por exportaciones. ${ }^{37}$ En el ámbito interno, Betancur estaba empeñado en procurar el diálogo y cese de las hostilidades con la guerrilla. Las relaciones con Cuba se constituyeron en una parte esencial de su política exterior y se cimentaron en la búsqueda de la pacificación en Centroamérica, Grupo de Contadora, el proceso

33 En su época fueron muy comentadas las declaraciones del presidente colombiano a Newsweek, en las que afirmó que el gobierno de Estados Unidos trataba con desdén a Colombia y añadió que el país no deseaba ser satélite de ninguna superpotencia. Newsweek, Internacional, 23 de agosto, 1982.

${ }^{34}$ Apolinar Díaz Callejas y Roberto González Arana, Colombia y Cuba. Del distanciamiento a la colaboración, Barranquilla, Uninorte, 1988.

35 Roberto González Arana, "La política exterior de Colombia a finales del siglo xx: primera aproximación", en Investigación y Desarrollo, vol. 12, núm. 2, 2004, pp. 258-285.

${ }^{36}$ Dallanegra "El Sistema Político..., pp. 6-32

${ }^{37}$ Postura similar fue adoptada por el presidente peruano Alan García Pérez, al asumir por primera vez en 1985 la presidencia. En su segundo periodo 2006-2011 se desdijo totalmente de esta posición. 
Luis Dallanegra Pedraza

de paz en Colombia y el tema de la deuda externa a partir del Consenso de Cartagena de $1985 .{ }^{38} \mathrm{El} \mathrm{liderazgo} \mathrm{y} \mathrm{acción} \mathrm{de} \mathrm{Betancur} \mathrm{en} \mathrm{política} \mathrm{exterior} \mathrm{permitie-}$ ron disipar las dudas sobre su nivel de compromiso con la agenda de paz e hicieron posible ganar credibilidad interna. Esto favoreció la firma de los acuerdos de paz con las Farc en marzo de 1984 y también buscó negociar con el M-19 y el eLs. ${ }^{39}$ Luego de un primer año exitoso, las acciones en materia internacional comenzaron a mostrar menos logros. Los fundamentos de la orientación estratégica de la política exterior empezaron a erosionarse como consecuencia de situaciones internas en asuntos como el narcotráfico, el sector externo de la economía y el proceso de paz con la guerrilla. Respecto de la deuda externa, de un multilateralismo en su tratamiento, se pasó a negociar de manera bilateral y se acordó un monitoreo con el FMI, al igual que el resto de América Latina, el denominado Consenso de Cartagena de 1985 fracasó. ${ }^{40}$

\section{Cá́da del MuRo de BerLín 1989}

\section{Continúa la "Diversificación" de la política externa}

El gobierno de Virgilio Barco Vargas, asumido en 1986, se caracterizó por un esfuerzo sistemático y programático de ampliación de las relaciones exteriores, sin consideraciones ideológicas. Patrocinó una diversificación y fomento de los vínculos económicos y comerciales con todas las naciones y bloques regionales.

${ }^{38}$ F. Cepeda, "La lucha por la autonomía: la gran encrucijada de la política exterior de Betancur", en H. Muñoz [comp.], América Latina y el Caribe: políticas exteriores para sobrevivir, en Anuario de Políticas Exteriores Latinoamericanas, Buenos Aires, GEL, 1986. p. 225; Luis Dallanegra Pedraza, Tendencias del Orden Mundial: Régimen Internacional, Buenos Aires, edición del autor, 2001, cap. IX.

${ }^{39}$ M. Chernick, "La política exterior de Colombia y su impacto sobre el proceso de paz y reconciliación nacional 1982-1986", en Documentos del CEI, Bogotá, Univerisdad de los Andes, septiembre-octubre de 1988, p. 27.

${ }^{40}$ Conducta similar fue adoptada por el resto de los países de la región, predominando la postura del secretario del Tesoro norteamericano James Baker 1985 y su posterior reemplazante Nicholas Brady 1989, cuyos planes fueron los aplicados al tratamiento de la deuda externa, bajo la premisa de que jamás sería pagada. Cepeda, "La lucha por la autonomía..., p. 225.

(MÉxxico 2012/1): 37-73

latino @mérica 54 
Consideraba que la mayor autonomía para el manejo de las relaciones exteriores, se determinaba por elementos económicos y no políticos. ${ }^{41}$ Muy similar al "desarrollismo" de Frondizi 1958-1962 en Argentina. Llevó a cabo una reorientación de la política exterior, ampliándola hacia la región del Pacífico. Atenuó el discurso de confrontación respecto de Estados Unidos y los organismos multilaterales de crédito, mediante un manejo conservador de la economía y trató de normalizar los vínculos con la banca mundial. Buscó un equilibrio entre las aspiraciones de una mayor autonomía y la resolución de los problemas económico-financieros de Colombia. ${ }^{42}$ Mantuvo la presencia del país en el MONOAL, considerándolo como "un elemento de equilibrio en el sistema internacional y de apertura al diálogo entre los países industrializados y los países en desarrollo", ${ }^{43}$ promoviendo la autonomía diplomática frente a Estados Unidos y no volver al alineamiento automático. Condenó la acción de Estados Unidos de invadir Panamá en 1989, y reclamó, junto a otros Estados de la región, la no intervención. Le otorgó gran interés a la Comunidad Europea bajo el concepto de que "la nueva realidad europea generará oportunidades y desafíos para América Latina. [...] Debemos ir como una sola América Latina al encuentro de una Europa unida" ${ }^{4}$

${ }^{41}$ J. A. Gálvez, "La política exterior colombiana: Una historia trágica", en Derecho y política internacional: retos para el siglo XXI, Barranquilla, Uninorte, 2003, p. 151.

${ }^{42}$ Chris J. Gonçalves y Andrés Soto, "Relaciones económicas entre Colombia y Estados Unidos: la búsqueda de mayor autonomía 1982-1992", en Colombia Internacional, núm. 19, Universidad de los Andes, julio-septiembre de 1992

${ }^{43}$ Virgilio Barco, "Una política exterior para el cambio", en Informe al Congreso Nacional, t. III, Bogotá, 1990, p. 69. Al respecto, el gobierno dictatorial de Jorge R. Videla de Argentina llevó a cabo una política similar, pretendiendo que el país se transformara en un "puente de conexión entre el Primer y el Tercer Mundo".

${ }^{44}$ Ibid.

latino \& mérica 54

(MÉxico 2012/1): 37-73 55 
Luis Dallanegra Pedraza

\section{"Desintegración" de la uRss 1991: fin del sistema bipolar}

La década de los noventa trajo como novedad el fin del sistema bipolar con la desintegración de la uRss en 1991, luego de la Cumbre de Reykjavik entre Ronald Reagan y Mikhail Gorbachev en 1985, que dio lugar al inicio del fin de la segunda Guerra Fría y la caída del Muro de Berlín en 1989. En lo económico, dio origen a la globalización, el Consenso de Washington de 1989, las privatizaciones, la apertura y el achicamiento del rol del Estado. Entre Estados Unidos y América Latina se modificó el "paradigma de relacionamiento hemisférico" de "seguridad y desarrollo" que dominó desde fines de la Segunda Guerra Mundial, con la Doctrina Truman hasta la Cumbre de Reykjavik en 1985, pasando a "democracia y desarrollo". Uno de los resultados del nuevo paradigma fue que Estados Unidos dejó de apoyar a las fuerzas armadas de la región, como "partido políico alternativo", utilizando la metodología de "democracia controlada o cooptada", y apoyó a los gobiernos civiles que se legitimaran por el voto, pero que fueran "funcionales" a sus intereses económicos y de seguridad. ${ }^{45}$

"Conveniencia" entre Respice Polum $y$ Respice Similia

El inicio del gobierno de César Gaviria en 1990 se dio en la etapa en que llegó a su fin el sistema bipolar. Desde su discurso de posesión, Gaviria manifestó que Colombia debería "ajustarse a las nuevas realidades de la política internacional" ${ }^{46}$ En su gobierno se gestó la Asamblea Nacional Constituyente que dio lugar a la Constitución de 1991. Intentó llevar a cabo una política exterior acorde con las nuevas circunstancias, que obligaban a la internacionalización de la economía en un mundo que se globalizaba, a la vez que procuraba el fortalecimiento de la capacidad negociadora de la región. A su política exterior le dio una impronta de "política exterior comercial", criterio seguido también por los go-

${ }^{45}$ Dallanegra "El Sistema Político..., pp. 6-32.

46 Ministerio de Relaciones Exteriores, República de Colombia, Memoria al Congreso Nacional, 1990-1991, t. I, Luis Fernando Jaramillo Correa, Bogotá, Imprenta Nacional, 1991. 
biernos chilenos desde Augusto Pinochet en adelante. Apoyó la "Iniciativa para las Américas" del presidente George H. W. Bush que luego Bill Clinton denominó Área de Libre Comercio para las Américas (ALCA), a la vez que se orientó a profundizar las relaciones comerciales en la región mediante el denominado Grupo de los Tres: Colombia, Venezuela y México. En la misma etapa en Argentina, el presidente Carlos Menem llevaba a cabo una política similar, al igual que Alberto Fujimori en Perú. Restableció las relaciones consulares con Cuba en 1991, acordando formalizar el comercio bilateral y la deuda que tenía con Colombia. Se pactó que pagase $50 \%$ de los costos de compras colombianas. ${ }^{47}$ Se creó la Asociación de Estados del Caribe en 1994 en la que participó Colombia, promoviendo el libre comercio, las políticas conjuntas frente a terceros estados e impulsar la cooperación en diversas áreas. Ese año Colombia tuvo la presidencia del MONOAL.

\section{Respice Polum con dificultades}

Al asumir el gobierno Ernesto Samper en 1994, la política exterior regresó a la vieja doctrina del Respice Polum. Esto se debió: 1. Al peso creciente de Estados Unidos en el sistema internacional en la etapa posbipolar, además de ser el principal socio comercial de Colombia; 2. Al fracaso de la integración latinoamericana, al impedir que la región desempeñe un rol significativo en el contexto mundial, más allá de retóricas. En la década de los noventa, gran parte de los países latinoamericanos privilegiaban sus relaciones bilaterales con Estados Unidos, debilitando la integración regional. México y Chile tuvieron un papel creciente en este sentido, al igual que Argentina con el gobierno de Carlos Menem; 3. A la importancia y significación que han tenido el Plan Colombia y la Iniciativa Andina para el fortalecimiento y reconstrucción del Estado y sus Fuer-

${ }^{47}$ El Tiempo, Bogotá, 21 de julio, 1991. En http://www.eltiempo.com/archivo/documento/MAM123469.

latino @mérica 54

(MÉxico 2012/1): 37-73 57 
Luis Dallanegra Pedraza

zas Armadas. ${ }^{48}$ Samper tuvo, desde sus inicios, grandes tropiezos y dificultades por el escándalo suscitado alrededor de los fondos para su campaña y su relación con el narcotráfico, lo que dio lugar al Proceso 8000 y derivó en unas muy difíciles relaciones con Estados Unidos. Desde 1995, cuando Samper asumió la presidencia del MONOAL, se suponía que esta oportunidad podría traer grandes beneficios. Debido a la finalización del conflicto Este-Oeste se generó una discusión sobre la utilidad o el sentido del MONOAL. ${ }^{49}$ Samper veía como una excelente oportunidad que Colombia presidiera dos organismos que agrupan tal cantidad de naciones como la OEA -César Gaviria - y los No Alineados; sin embargo, preocupado por el deterioro de las relaciones con Estados Unidos, luego de conocerse las denuncias sobre filtración de fondos del narcotráfico en su campaña presidencial, trató de analizar la relevancia de presidir al MONOAL a la luz de sus vínculos con el gobierno de Estados Unidos, incluso llegó a pensar en la posibilidad de renunciar a la designación, pero el análisis de las consecuencias que este compromiso había traído para Indonesia - anterior presidente del MONOALlo llevó a la conclusión de que, en vez de agrietar las relaciones con Estados Unidos, podría significar un buen medio y una buena oportunidad para transformarse en un mediador a favor de ese país ante los miembros más radicales del movimiento. ${ }^{50}$ Pensó que el aumento de la influencia internacional del país, al presidir el MONOAL, se iba a convertir en una fortaleza para ganar terreno en las relaciones con Estados Unidos. En contraste, los desajustes estructurales del régimen liberal, el cuestionamiento por corrupción, la falta de garantías a los derechos humanos en el conflicto interno, el escándalo por la influencia del

${ }^{48}$ Eduardo Pizarro Leongómez, "Washington y América Latina”, en El Tiempo, Bogotá, 28 de abril, 2003. En http://eltiempo.terra.com.co/opinion/colopi/2003-04-28/ARTICULO-WEB-NOTA_INTERIOR-1070906.html.

49 "Los No Alineados: beneficios, oportunidades y problemas en el nuevo orden mundial", en Revista Análisis Político, núm. 25, Instituto de Estudios Políticos y Relaciones Internacionales (IEPRI) mayo-agosto de 1995.

${ }^{50}$ S. Ramírez, "Colombia en el Movimiento de los No Alineados", en S. Ramírez y L. A. Restrepo [coord.], Colombia: entre la reinserción y el aislamiento, Bogotá, Siglo del Hombre, 1997, p. 167. 
narcotráfico, contribuyeron a desdibujar el activismo político en el MONOAL y enturbiaron las relaciones con el gobierno de Estados Unidos.

En 1998 asumió la presidencia Andrés Pastrana, cuyo eje central fue la búsqueda de la paz con los grupos guerrilleros, al involucrar a la comunidad internacional con la creación e implementación del llamado Plan Colombia. Las relaciones con Estados Unidos se normalizaron, luego del turbulento periodo de Ernesto Samper. Para algunos ex funcionarios del gobierno de Pastrana, la estrecha relación de Colombia con Estados Unidos durante su mandato, se constituiría en "el logro del más alto nivel de cooperación económica, política, militar y social" del país. ${ }^{51}$ En 2002 apoyó la creación del alCa y el ingreso de Colombia, ya que el comercio exterior colombiano rondaba $75 \%$ con los países que serían miembros de ese proceso. Viajó a Estados Unidos en octubre de 1998 para suscribir la llamada Alianza Contra las Drogas Ilícitas, que sería el eje de las relaciones bilaterales durante su cuatrienio, comprometiéndose a: 1. Reducir el consumo de drogas con programas de prevención; 2. Aumentar la eficiencia de las entidades nacionales en la lucha contra el narcotráfico; 3 . Liderar acciones para desmantelar a las organizaciones de narcotráfico; 4. Utilizar la extradición; 5. La erradicación de los cultivos ilícitos; 6 . Mejorar la capacidad operativa de las Fuerzas Militares y la Policía para perseguir el lavado de activos, el tráfico de armas y el narcotráfico. ${ }^{52}$ La postura del gobierno norteamericano fue expresada por Thomas Pickering, tercer funcionario del Departamento de Estado norteamericano, en agosto de 1999, quien transmitió la preocupación de la Casa Blanca ante el manejo de la "zona de despeje" en el Caguán, que debía ser desmilitarizada, pues tenía conocimiento de que se llevaban a cabo actividades ilícitas, como secuestros, asesinatos y que las FarC se habían rearmado. ${ }^{53}$ Para continuar con el apoyo a Colombia, Estados Unidos proponía que el gobierno

${ }^{51}$ G. Fernández de Soto, "Logros de la política exterior de Colombia: 1998-2002", en Colombia Internacional, núm. 53, Universidad de los Andes, 2002, p. 92.

${ }^{52}$ C. Ahumada, Cuatro años a bordo de sí mismo: la berencia económica, social y política del gobierno de Andrés Pastrana, Bogotá, El Ancora, 2002, p. 272.

53 María O 'Donnell, "Estados Unidos: Colombia no será otro Vietnam", en La Nación, Buenos Aires, 26 de agosto, 2000. En http://www.lanacion.com.ar/nota.asp?nota_id=30461. 
Luis Dallanegra Pedraza

diseñara un plan coherente para la lucha contra el narcotráfico. Pastrana aceptó, y se redactó el Plan Colombia ${ }^{54}$ que se convirtió en el mayor receptor de ayuda militar norteamericana del continente..$^{55}$ De acuerdo con el presidente Bill Clinton, Colombia era el epicentro mundial del narcotráfico y, por tanto "representaba una amenaza extraordinaria a la seguridad nacional de Estados Unidos". ${ }^{56}$ El Parlamento europeo en febrero de 2001 expresó ciertos reparos al Plan Colombia, por su carácter belicista y por ser una forma de intervención en los asuntos internos de otro Estado. ${ }^{57}$ Los analistas del conflicto plantearon que el fracaso del proceso de paz con las FARC, impulsado por Pastrana, se debió a que la guerrilla veía con mucho recelo la intromisión del gobierno de Estados Unidos en la militarización del país; la creciente participación de paramilitares y la adopción del Plan Colombia. ${ }^{58}$

Inicio de la LuCha Mundial Contra el Terrorismo:

Post 11 de Septiembre de 2001

Respice Polum como negación del Respice Similia

En 2002 asumió el poder Alvaro Uribe Vélez, un conservador en lo formal, pero desde el punto de vista de su política "uribista" ni liberal ni conservador. La ruptura del proceso de paz con las FaRC en febrero de 2002 suscitó la articulación de

${ }^{54}$ Arlene Tickner, "La guerra contra las drogas: las relaciones Colombia-Estados Unidos durante la administración Pastrana”, en J. Estrada Álvarez [ed.], Plan Colombia, ensayos críticos, Bogotá, Universidad Nacional de Colombia, 2001, pp. 217-223.

55 Noam Chomsky, "Móviles y consecuencias: crítica al Plan Colombia", en El Espectador, Bogotá, Lecturas Dominicales, 6 de agosto, 2000.

${ }^{56}$ El Tiempo, Bogotá, 23 de octubre, 1995.

${ }^{57}$ Marco Alberto Romero, "La nueva internacionalización del conflicto y los procesos de paz", en J. Estrada, El Plan Colombia: ensayos críticos, Bogotá, Universidad Nacional de Colombia-Facultad de Derecho y Ciencias Sociales, 2001.

${ }^{58}$ Camilo Gonzáles Posso, "El Caguán Irrepetible: Párrafo 7", en INDEPAZ, Instituto de Estudios para el Desarrollo y la Paz, Colombia, 2008. En http://www.indepaz.org.co; Alberto Pinzón Sánchez, "El Pos-Caguán", en Anncol, Agencia de Noticias Nueva Colombia. En http://www.anncol.eu/columnistas/21/-pos-caguán-982 (fecha de consulta: 15 de octubre, 2010). 
un nuevo discurso colombiano, de carácter antiterrorista, vinculándolo a la lucha global que llevaba a cabo Estados Unidos. Desde el comienzo de su mandato tuvo como objetivo de su política exterior vincular el conflicto armado a la cruzada internacional liderada por el presidente George W. Bush contra el terrorismo. ${ }^{59}$ Esta etapa se ha caracterizado por el presidencialismo y el personalismo como rasgos sobresalientes, haciendo de la política internacional un ejercicio primario y parroquial. ${ }^{60} \mathrm{El}$ "vértice" de la política exterior fue Estados Unidos y el "vértice" del conflicto ha sido América Latina, especialmente los países vecinos. Modificó el uso tradicional del Respice Polum al intensificar la "guerra contra las drogas" siguiendo las pautas establecidas por el gobierno norteamericano, al ampliar la "invitación" a ese pais ${ }^{61}$ para que participara también en el Plan Patriota ${ }^{62}$ y al representar la situación en Colombia como una amenaza para la seguridad regional. Todas sus políticas se orientaron a aislar al país de América Latina. Apoyó la creación del ALCA, en los tiempos en que "Lula" Da Silva en Brasil y Néstor Kirchner ${ }^{63}$ en Argentina estaban en contra, debido a que el gobierno de Estados Unidos mantenía subsidios agrícolas junto con los países de la Unión Europea, perjudicando las economías de la región. La oposición a la propuesta norteamericana quedó planteada en la IV Cumbre de las Américas que se cele-

59 Arlene Tickner y Rodrigo Pardo, "En busca de aliados para la Seguridad Democrática: la política exterior del primer año de la Administración de Uribe", en Revista Colombia Internacional, núms. 56-57, CEI, Universidad de los Andes, septiembre 2002-junio 2003.

${ }^{60}$ María Jimena Duzán, Así gobierna Uribe, Bogotá, Planeta, 2004, p. 75.

${ }_{61}$ Arlene B. Tickner, "Intervención por invitación: claves de la política exterior colombiana y de sus debilidades principales", en Revista Colombia Internacional, núm. 65, Universidad de los Andes, enero-junio, 2007; Ángel Ricardo Sánchez, "Claves de la ilegitimidad", en Revista CEPA, núm. 3, Dirección Orlando Fals Borda, abril de 2007.

${ }^{62}$ Ampliación del Plan Colombia en el que se incorporó el concepto de "Seguridad democrática", variación del modelo de la "Doctrina de la Seguridad Nacional" aplicada en América Latina en la etapa de la Guerra Fría, justificando la instalación de dictaduras militares en el Cono Sur bajo el concepto de la "lucha contra el comunismo". J. Cotler \& R. Fagen, Relaciones politicas entre América Latina y Estados Unidos, Buenos Aires, Amorrortu, 1974. También, Finer, S. E. Los militares en la politica mundial, Buenos Aires, Sudamericana, 1969. Igualmente, E. Nordlinger, Soldiers in Politics: Military Coup and Governments, Prentice-Hall, 1977.

${ }^{63}$ Pasada la etapa "menemista" de desindustrialización, desnacionalización y de alineamiento subordinante con Estados Unidos. 
Luis Dallanegra Pedraza

bró en Mar del Plata, Argentina, en noviembre de 2005 en la que hubo 29 países en contra del alCa y 5 a favor junto a Estados Unidos, entro ellos, Colombia y Panamá. Además, el gobierno de Uribe planteó la firma de un Tratado de Libre Comercio (TLC) con Estados Unidos, al estilo del que ya tenía vigencia entre aquél país y Chile y la importancia de ingresar como miembro al Foro para la Cooperación Económica entre los países de Asia y el Pacífico (APEC por sus siglas en inglés). El $1^{\circ}$ de julio de 2002 entró en vigencia el Estatuto de Roma, que dio lugar al nacimiento de la Corte Penal Internacional (CPI) para entender sobre crímenes de lesa humanidad. ${ }^{64}$ Entre los ratificantes ${ }^{65}$ del Estatuto de Roma, se encuentra Colombia, pero haciendo reserva del Artículo 124 que excluye de la competencia del Tribunal el conocimiento de los llamados crímenes de guerra, en una declaración ante la Secretaría General de la onu. El criterio, en principio, era facilitar un proceso de paz en Colombia, toda vez que permite otorgar inmunidad a los implicados en violaciones de los derechos humanos e impide a la cPI durante un periodo de siete años, juzgar aquellos delitos contra personas o bienes protegidos por el Derecho Internacional Humanitario cometidos por colombianos o en territorio colombiano. ${ }^{66}$ En julio de 2003 Uribe celebró un acuerdo con las Autodefensas Unidas de Colombia (Auc) en Santa Fe de Ralito y en mayo de 2004 un acuerdo complementario, en el que se establecieron las bases de la desmovilización de los paramilitares. ${ }^{67}$ En junio de 2005 se adoptó

${ }^{64}$ Mientras la cPi es el tribunal de justicia que entiende de crímenes contra la humanidad cometidos por personas, la Corte Internacional de Justicia de La Haya entiende de conflictos entre estados.

${ }_{65}$ La vigencia y relevancia de la cPi es relativa, ya que países como Estados Unidos, China, Egipto, India, Israel, entre otros, no la ratificaron, y no se aplica para crímenes de lesa humanidad cometidos por personas de esos países. El gobierno norteamericano firmó acuerdos bilaterales de inmunidad con 60 países, comprometiéndolos a que no entreguen ciudadanos norteamericanos a la cPI sino a Estados Unidos. Mientras Estados Unidos se niega a que se aplique a sus ciudadanos, está de acuerdo con que se aplique a otras personas en el mundo, tal el caso de Muammar Khadafy por ejemplo.

${ }^{66}$ Andrea Paola Fernández y Victoria Carolina Gómez S., La Corte Penal Internacional en Colombia. En http://www.presidencia.gov.co/sne/2005/altocom/ensayo13.htm.

${ }^{67}$ Los Acuerdos de Santa Fé de Ralito I y II entre el gobierno nacional y las auc. En http://uisdallanegra. bravehost.com/Tratados/acsfera1.htm y http://uisdallanegra.bravehost.com/Tratados/acsfera2.htm. 
la Ley 975 de Justicia y Paz, como marco jurídico para la reinserción de las Auc. Esta ley generó comentarios encontrados tanto en el marco nacional como por ONG de derechos humanos y diferentes estados, especialmente europeos, debido a que era vista como una forma encubierta de amnistiar a los paramilitares, ya que les garantiza una pena simbólica -5 a 8 años - a cambio de la confesión de sus crímenes. La Corte Constitucional declaró inexequible el artículo 71 de la Ley de Justicia y Paz, que establecía que la actividad de los paramilitares caía bajo el concepto de "sedición". La Corte Suprema de Justicia dijo que las acciones de los paramilitares no podían considerarse delitos políticos. ${ }^{68}$

\section{DE "EsPaLDAS" a AmÉRICA LATINA}

Así como se acercó a Estados Unidos se alejó de América Latina por diferentes motivos: con Chávez por causas ideológicas y desentendimientos respecto del manejo del proceso con las FARC; con Correa por el ataque, sin previo aviso, del campamento de Raúl Reyes en la frontera entre ambos países. ${ }^{69} \mathrm{El}$ canciller brasileño, Celso Amorin, expresó la tristeza del presidente brasileño, Luis Inacio "Lula" Da Silva, "por la tensión y disputa entre dos países hermanos", y calificó de "rechazable y condenable" la invasión de la territorialidad de otro país: "No se puede permitir bajo ningún concepto y por eso Brasil condenó la incursión colombiana en territorio ecuatoriano". Hugo Chávez comparó la política exterior de Uribe con la del gobierno de Bush: "Colombia reivindica un principio de soberanía que se inventaron ellos. Están reivindicando el derecho a lo que ellos llaman combatir el terrorismo donde esté. Es la misma doctrina de Bush, que fue la que conllevó a invadir a Afganistán e Irak". Llamó a Uribe a revisar esa doctrina porque podría "conllevar a una hecatombe en la región".70 En agosto

${ }^{68}$ Luis Dallanegra Pedraza, ¿Pax o Paz en América Latina?: Conflicto en Colombia, 2006. En http://uisdallanegra.bravehost.com/Amlat/cpconf08.htm.

${ }^{69}$ Luis Dallanegra Pedraza, ¿Pax o Paz en América Latina?: Conflicto en Colombia, 2007. En http://uisdallanegra.bravehost.com/Amlat/cpconf09.htm.

${ }^{70}$ Luis Dallanegra Pedraza, ¿Pax o Paz en América Latina?: Conflicto en Colombia, 2008. En http://uisdallanegra.bravehost.com/Amlat/cpconf10.htm. 
Luis Dallanegra Pedraza

de 2009 volvieron a enturbiarse las relaciones entre Colombia y sus vecinos sudamericanos, debido al traslado de bases militares norteamericanas de Manta Ecuador a Colombia. El gobierno brasileño y otros de la región expresaron su preocupación por la instalación de esas bases militares. El ministro de Defensa colombiano, Juan Manuel Santos, dijo tras la reunión con los enviados brasileños, que su gobierno "no consulta con otros países sus acuerdos bilaterales", aunque destacó que sí está abierto a compartir información. Se celebró una Cumbre de la unasur para tratar la temática. El presidente Uribe logró impedir que el organismo regional expresara su rechazo completo al acuerdo militar con Estados Unidos. ${ }^{71} \mathrm{El}$ conflicto en Colombia fue profundamente militarizado por el gobierno de Uribe, quien no ha querido llevar las cosas al terreno de la negociación. La solución política con base en las negociaciones estuvo fuera de su agenda de gobierno. ${ }^{72}$

\section{RESPICE SIMILIA PARA RESPICE POLUM}

En 2010 asumió la presidencia el ex ministro de Defensa de Uribe, Juan Manuel Santos, quien incursionó en la política como miembro del Partido Liberal. Consolidado el gobierno de Uribe, Santos dejó el Partido Liberal y fue uno de los creadores del Partido Social de Unidad Nacional, conocido como "Partido de la U". Frente al aislamiento político y estratégico del mandato de Uribe, su heredero, Juan Manuel Santos ha mostrado un nuevo estilo, cambiando las estrategias, aunque manteniendo las políticas. Luego del gobierno de la "Seguridad democrática" de Uribe, Santos bautizó su programa de gobierno como "Prosperidad democrática". Continúa con el Respice Polum y utiliza el Respice Similia para bajar el nivel de tensiones con los vecinos, que se habían creado en la gestión de Uribe, sin que ello signifique una posición más latinoamericanista. La reforma principal de este presidente está en las relaciones internacionales, ahora más

${ }^{71}$ Dallanegra, Realismo-Sistémico-Estructural...

${ }^{72}$ Gerardo Molina, "La violencia, el ejército y la nación", en La formación del Estado en Colombia y otros textos políticos, Bogotá, Universidad Externado de Colombia, 2004, p. 99. 
integradas con Latinoamérica, pero privilegiando los vínculos con Estados Unidos. Planteó como propósitos fundamentales de su gobierno reconstruir las relaciones con Venezuela y Ecuador, restablecer la confianza y privilegiar la diplomacia y la prudencia. Según Santos, a pesar de las diferencias ideológicas, se pueden tener buenas relaciones con los demás países si están basadas "en el respeto mutuo, la cooperación recíproca y la firmeza contra los criminales". Ofreció un diálogo a las guerrillas: "A los grupos armados ilegales [...] les digo que mi gobierno estará abierto a cualquier conversación que busque la erradicación de la violencia y la construcción de una sociedad más próspera, equitativa y justa. Es la hora de enterrar los odios". Entre las condiciones para dialogar, mencionó que deben renunciar al secuestro, al narcotráfico, a la extorsión, al reclutamiento de menores y al uso de minas antipersonales. De todas formas, no aceptó la desmilitarización del conflicto, por lo que continúa agravándose, muy lejos de la posibilidad de negociación y también de alcanzar una desmovilización. Una vez instalado el gobierno de Santos, las farc enviaron una carta a las autoridades de la unASUR para entablar un diálogo de paz gobierno-guerrilla, pero el gobierno calificó de inadmisible la propuesta, ya que previamente deben dar muestras de paz si quieren una salida política: "con los terroristas no se dialoga”. Fortaleció la presencia de Colombia en la unasur, después de la casi ruptura durante el gobierno de Uribe quien amenazó con retirarse del organismo. A fines de agosto de 2010 los cancilleres de Venezuela, Nicolás Maduro, y de Colombia, María Angela Holguín, se reunieron en Caracas con el objeto de instalar comisiones bilaterales para restablecer sus relaciones diplomáticas. El presidente Santos contrariamente a su antecesor Uribe, evita asociar a Chávez con la guerrilla. Dentro del proceso de normalización de las relaciones, firmaron en Cartagena 16 acuerdos de cooperación e integración en áreas que tienen que ver con proyectos de infraestructura, orientados a fortalecer la integración, construcción de poliductos, oleoductos y carreteras, comercio, pago de exportaciones a empresarios colombianos, creación de empresas de salud, turismo, desarrollo fronterizo, suministro de combustibles y lucha antinarcóticos. Acordaron buscar la normalización de la situación de Honduras y su reingreso a la OEA, que había quedado excluida por el voto mayoritario latinoamericano luego 
Luis Dallanegra Pedraza

del golpe de Estado a Manuel Zelaya. En septiembre los gobiernos de Colombia y Brasil firmaron ocho acuerdos de cooperación en las áreas de desarrollo fronterizo y de seguridad, durante una visita de Juan Manuel Santos. Agradeció al presidente "Lula" Da Silva la posición de rechazo al terrorismo. Se sentaron las bases para una futura cooperación bilateral en el área militar, con la firma de un acuerdo de intenciones para la participación de Colombia en la construcción de un avión de transporte brasileño similar al Hércules C-130. Santos valoró la cooperación y reiteró su convicción de que la próxima será "la década de América Latina" e instó a "apostar a la unidad, que debe estar por encima de cualquier diferencia ideológica o política". La región tiene por delante los "grandes retos" de "reducir la pobreza y la falta de equidad entre sus pueblos", para los que "llegó el momento de despertar" y "acceder por fin a la prosperidad económica y social". En noviembre de 2010 Colombia y Ecuador retomaron las relaciones diplomáticas. En julio de 2011 acordaron reestructurar un Comité de Integración Fronteriza. En mayo de 2011, el presidente Santos reconoció que "en Colombia existe conflicto armado y no una amenaza terrorista", pese a las críticas del ex presidente Uribe, concepto que se presentó para su inclusión dentro de la Ley de Víctimas, a fin de evitar que en la reparación a las víctimas se filtren personas afectadas por la delincuencia común. Santos aclaró que no se estaba haciendo una adición a algo que se tenía en el pasado sino que continúa una situación muy clara: que las Fuerzas Armadas están operando bajo el Derecho Internacional Humanitario que presupone un conflicto armado interno. "Reconocer el conflicto, de ninguna manera significa que los terroristas dejen de ser terroristas porque ellos son terroristas porque cometen actos de terrorismo. De ninguna manera significa que les vamos a dar un reconocimiento especial y mucho menos que estamos allanando el terreno para la beligerancia". ${ }^{73}$

73 Luis Dallanegra Pedraza, ¿Pax o Paz en América Latina?: Conflicto en Colombia, 2011. En http://uisdallanegra.bravehost.com/Amlat/cpconf13.htm. También Diego Cardona, "Una nueva política exterior en Colombia: el primer año de la Administración Santos", en Nueva Sociedad, núm. 233, Friedrich Ebert Stiftung, mayo-junio de 2011.

(Méxxco 2012/1): 37-73

latino @mérica 54 


\section{CONCLUSIÓN: LOS VAIVENES DE LA POLÍTICA EXTERIOR COLOMBIANA}

La tendencia a utilizar la Doctrina del Respice Polum o Respice Similia no es patrimonio exclusivo de ninguno de los partidos tradicionales. Hubo dos gobiernos conservadores que siguieron la Doctrina del Respice Polum: Marco Fidel Suárez-ideólogo de la Doctrina-y Andrés Pastrana Arango. Una administración conservadora estuvo caracterizada por la Doctrina del Respice Similia: Belisario Betancur. En el Partido Liberal hubo tres administraciones cercanas al Respice Similia: Carlos Lleras Restrepo, Alfonso López Michelsen - mentor del conceptoy Ernesto Samper Pizano y varias administraciones al Respice Polum: Olaya Herrera, Eduardo Santos, Alberto Lleras Camargo, Julio César Turbay Ayala y la administración de Alvaro Uribe, disidente del Partido Liberal, con políticas conservadoras que usó la Doctrina del Respice Polum, como método de negación del Respice Similia. Hay ciertas administraciones de carácter mixto: la de César Gaviria, cercano a la idea del libre comercio planteada por Estados Unidos, pero con una gestión multilateral de la política exterior; y la de Virgilio Barco. Juan Manuel Santos hace uso tanto del Respice Polum como del Respice Similia, pero mantiene sus vínculos preferenciales con Estados Unidos. Ninguno de los dos partidos ha llevado a cabo políticas orientadas a la "construcción de poder" para resolver los problemas de desarrollo interno y mejorar la inserción internacional, independientemente de que hubo algunos escasos gobiernos que favorecieron las relaciones "Sur-Sur", aunque de manera más retórica que realista, a la vez que sus decisiones fueron anuladas por políticas de gobiernos posteriores. En general, los gobiernos colombianos -al igual que la gran mayoría de los latinoamericanos- han mantenido vínculos "racionales" de subordinación, convencidos de que resulta más ventajoso relacionarse con la potencia hegemónica que con los países de la región. Ninguno de los gobiernos ha tenido una noción clara sobre el funcionamiento de la estructura internacional, más allá de sus visiones "juridicistas-institucionalistas". Con excepciones, los gobiernos co- 
Luis Dallanegra Pedraza

lombianos han desarrollado una política externa "corporativa" - sea que privilegien intereses de partido o de grupos de poder económicos-, donde el Estado ha sido más instrumento de esos intereses que destinatario.

Recibido: 3 de agosto, 2011. Aceptado: 13 de febrero, 2012.

Bibliografía

Libros

AHUMADA, C., Cuatro años a bordo de sí mismo: la berencia económica, social y política del gobierno de Andrés Pastrana, Bogotá, El Ancora, 2002.

Ardila, Martha, Diego Cardona y Arlene B. Tickner, Prioridades y desafíos de la politica exterior colombiana, Bogotá, Friedrich Ebert Stiftung, 2002.

Barco, Virgilio, "Una política exterior para el cambio", en Informe al Congreso Nacional, t. III, Bogotá, 1990.

Bethell, Lesie [ed.], The Cambridge History of Latin America, vol. III., Cambrige, Cambridge University Press, 1985.

Caicedo Castllla, José J., El Panamericanismo, Buenos Aires, Roque Depalma Editor, 1961.

CEPEDA F., "La lucha por la autonomía: la gran encrucijada de la política exterior de Betancur", en H. Muñoz [comp.], América Latina y el Caribe: políticas exteriores para sobrevivir, Buenos Aires, GEL, 1986.

Cepeda Ulloa, F. y R. PARdo, "La política exterior colombiana 1974-1986", en Nueva Historia de Colombia, Bogotá, Planeta, 1989.

COTLER, J. \& Fagen, R., Relaciones políticas entre América Latina y Estados Unidos, Buenos Aires, Amorrortu, 1974.

Cuevas Cancino, Francisco, Roosevelt y la buena vecindad, México, FCe, 1954.

(México 2012/1): 37-73

latino @mérica 54 
Dallanegra Pedraza, Luis, El orden mundial del siglo xxi, Buenos Aires, Ediciones de la Universidad, 1998.

,Tendencias del Orden Mundial: Régimen Internacional, Buenos Aires, edición del autor, 2001.

, Realismo-Sistémico-Estructural: Política Exterior como "Construcción" de Poder, Córdoba, edición del autor, 2009.

Relaciones Políticas entre Estados Unidos y América Latina: ¿Predominio "Monroista" o Unidad Americana?, Buenos Aires, edición del autor, 1994.

Díaz Callejas, Apolinar, Roberto González Arana, Colombia y Cuba, del distanciamiento a la colaboración, Barranquilla, Uninorte, 1988 (Colciencias).

Duzán, María Jimena, Así gobierna Uribe, Bogotá, Planeta, 2004.

Finer, S. E., Los militares en la política mundial, Buenos Aires, Sudamericana, 1969.

FIORI, J. L., O poder global e a nova geopolítica das nações, São Paulo, Boitempo, 2007.

Gálvez Valega, Arturo, Sistema Interamericano de Defensa, Barranquilla, Uninorte, 2002.

Gálvez, J. A., "La política exterior colombiana: una historia trágica", en Derecho y política internacional: retos para el siglo XXI, Barranquilla, Uninorte, 2003.

García, EdUARDO A., La política internacional de la república, Buenos Aires, Emecé, 1964.

González, Camilo et al., "Ensayos de Paz", en Indepaz, Bogotá, Punto de Encuentro, 2008.

Mesa, DARío, "La vida política después de Panamá", en Manual de Historia de Colombia, t. III, Bogotá, Instituto Colombiano de Cultura, 1980.

Ministerio de Relaciones Exteriores, República de Colombia. Memoria al Congreso Nacional, 1990-1991, t. I, Luis Fernando Jaramillo Correa, Bogotá, Imprenta Nacional, 1991.

MOLINA, GERARDO, La violencia, el ejército y la nación, en La formación del Estado en Colombia y otros textos políticos, Bogotá, Universidad Externado de Colombia, 2004.

latino mérica 54

(MÉxıco 2012/1): 37-73 69 
Luis Dallanegra Pedraza

NoRDLINGER, E., Soldiers in Politics: Military Coup and Governments, Englewood Cliffs, N. J., Prentice-Hall, 1977.

Ospina VÁsQuez, LuIs, Industria y protección en Colombia, 1810-1930, Medellín, E.S.F., 1955.

PARDo, Rodrigo, "La política exterior", en Fernando Cepeda Ulloa [ed.], Fortalezas de Colombia, Bogotá, Planeta/Banco Interamericano de Desarrollo, 2004.

Puig, Juan Carlos, "Tendencias de la política exterior argentina", en Doctrinas internacionales y autonomía latinoamericana, Caracas, Universidad Simón Bolívar, 1980.

Ramírez, S., "Colombia en el Movimiento de los No Alineados", en S. Ramírez y L. A. Restrepo [coords.], Colombia: entre la reinserción y el aislamiento, Bogotá, Siglo del Hombre, 1997.

RIvas, Raimundo, Historia diplomática de Colombia 1810-1934, Bogotá, Ministerio de Relaciones Exteriores/Imprenta Nacional, 1961.

Romero, Marco Alberto, "La nueva internacionalización del conflicto y los procesos de paz", en J. Estrada, El Plan Colombia: ensayos críticos, Bogotá, Universidad Nacional de Colombia, 2001.

SÁnchez Camacho, Jorge, Marco Fidel Suárez: biografía, Bucaramanga, Imprenta del Departamento, 1955.

Tickner, ARLene, "La guerra contra las drogas: las relaciones Colombia-Estados Unidos durante la Administración Pastrana", en J. Estrada Álvarez [ed.], Plan Colombia, ensayos críticos, Bogotá, Universidad Nacional de Colombia, 2001.

Zapata Cuéncar, Heriberto Marco, Fidel Suárez, Medellín, Copymundo, 1981.

\section{Revistas}

CARDONA, Diego, Una nueva política exterior en Colombia: el primer año de la Administración Santos, en Nueva Sociedad, núm. 233, Friedrich Ebert Stiftung, mayo-junio de 2011. 
Dallanegra Pedraza, Luis, "El Sistema Político Latinoamericano", en Revista Reflexión Política, vol. V, núm. 10, Bogotá, Instituto de Estudios Políticos, Universidad Nacional Autónoma de Bucaramanga, diciembre de 2003, pp. 6-32.

Fernández de Soto, G., "Logros de la política exterior de Colombia: 1998-2002", en Colombia Internacional, núm. 53, Universidad de los Andes, 2002.

GonçALVES, CHRis J y AndRés Soto, "Relaciones económicas entre Colombia y Estados Unidos: la búsqueda de mayor autonomía 1982-1992", en Colombia Internacional, núm. 19, Universidad de los Andes, julio-septiembre de 1992

González ARANA, RoBerto, "La política exterior de Colombia a finales del siglo xx: primera aproximación", en Investigación y Desarrollo, vol. 12, núm. 2, 2004, pp. 258-285.

LOWENTHAL, ABRAHAN, "El fin de la presunción hegemónica", en Estudios Internacionales, vol. I, núm. 37, 1977.

Revista Análisis Político, núm. 25, Sección Debates: Los No Alineados: beneficios, oportunidades y problemas en el nuevo orden mundial, reportajes a: Héctor Charry, Rodrigo Pardo y Socorro Ramírez, IEPRI, mayo-agosto de 1995.

Ś́nchez Angel, Ricardo, "Claves de la ilegitimidad", en Revista CEPA, núm. 3, abril de 2007.

TickNer, ARLENE B., "Intervención por invitación: claves de la política exterior colombiana y de sus debilidades principales", en Revista Colombia Internacional, núm. 65, Universidad de los Andes, enero-junio de 2007.

, "Tensiones y contradicciones en los objetivos de la política exterior estadounidense en Colombia: consecuencias involuntarias de la política antinarcóticos de Estados Unidos en un Estado débil", en Revista Colombia Internacional, núms. 49/50, Universidad de los Andes.

Tickner, Arlene B. y Rodrigo Pardo, "En busca de aliados para la 'Seguridad Democrática': la política exterior del primer año de la Administración de Uribe", en Revista Colombia Internacional, núms. 56/57, Universidad de los Andes, septiembre de 2002. 
luis Dallanegra Pedraza

\section{Documentos}

Chernick, M., "La política exterior de Colombia y su impacto sobre el proceso de paz y reconciliación nacional 1982-1986", en Documentos del CEI, Bogotá, Universidad de los Andes, septiembre-octubre de 1988, p. 27.

NASI, C., "La política internacional de Colombia hacia Cuba y Nicaragua durante el gobierno del presidente Julio César Turbay Ayala, 1978-1982", en Documentos CEI, núm. 9, Universidad de los Andes, mayo-junio de 1989, p. 16.

\section{Hemerografía}

CHOmsкr, Noam, "Móviles y consecuencias: crítica al Plan Colombia", en El Espectador, núms. 6/8, Bogotá, 2000

El Tiempo, Bogotá, 21 de julio, 1991. En http://www.eltiempo.com/archivo/documento/MAM-123469.

El Tiempo, Bogotá, 23 de octubre, 1995.

Newsweek, 23 de agosto, 1982.

O'DonNell, María, "Estados Unidos: Colombia no será otro Vietnam", en La Nación, Buenos Aires, 26 de agosto, 2000. En http://www.lanacion.com.ar/ nota.asp?nota_id $=30461$.

PizarRo LeongómeZ, Eduardo, "Washington y América Latina", en El Tiempo, Bogotá, 28 de abril, 2003. En http://eltiempo.terra.com.co/opinion/colopi/200304-28/ARTICULO-WEB-NOTA_INTERIOR-1070906.html.

\section{Páginas en Internet}

Dallanegra Pedraza, Luis, ¿Pax o Paz en América Latina?: Conflicto en Colombia, 2006. En http://uisdallanegra.bravehost.com/Amlat/cpconf08.htm. , ¿Pax o Paz en América Latina?: Conflicto en Colombia, 2007. En http://uisdallanegra.bravehost.com/Amlat/cpconf09.htm. , ¿Pax o Paz en América Latina?: Conflicto en Colombia, 2008. En http://uisdallanegra.bravehost.com/Amlat/cpconf10.htm.

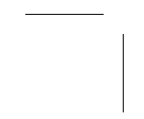


¿Pax o Paz en América Latina?: Conflicto en Colombia, 2009. En http://uisdallanegra.bravehost.com/Amlat/cpconf11.htm. ¿Pax o Paz en América Latina?: Conflicto en Colombia, 2011. En http://uisdallanegra.bravehost.com/Amlat/cpconf13.htm. FERnÁNDEZ, ANDREA PAOLA, Victoria Carolina Gómez S., La Corte Penal Internacional en Colombia. En http://www.presidencia.gov.co/sne/2005/altocom/ensayo13.htm.

Gonzáles Posso, Camilo, "El Caguán Irrepetible: Párrafo 7", en indePaz, Instituto de Estudios para el Desarrollo y la Paz, Bogotá, 2008. En http://www.indepaz.org.co.

NeIRA FERnÁNDEZ, EnRIQue, "Colombia: política exterior", en Observatorio de Política Internacional, "FRONTERA". En http://www.saber.ula.ve/bitstream/ 123456789/13635/1/ colombia_10042008.pdf (fecha de consulta: 14 de abril, 2008).

Pinzón SÁnchez, Alberto, "El Pos-Caguán, en Anncol", en Agencia de Noticias Nueva Colombia. En http://www.anncol.eu/columnistas/21/1-pos-caguán982 (fecha de consulta: 15 de octubre, 2010).

Santa Fé de Ralito I y II entre el Gobierno nacional y las Auc. En http://uisdallanegra.bravehost.com/ Tratados/acsfera1.htm. 
Dallanegra_revista latinoamerica 06/06/12 11:52 Página 74

(4) 